\title{
A STEREOLOGICAL ANALYSIS OF THE EFFECT OF EARLY POSTNATAL ETHANOL EXPOSURE ON NEURONAL NUMBERS IN RAT DENTATE GYRUS
}

\author{
TAKANORI MIKI ${ }^{1}$, SIMON J HARRIS $^{2}$, PETER WILCE $^{3}$, YOSHIKI TAKEUCHI $^{1}$ AND KULDIP S BEDI ${ }^{2}$ \\ ${ }^{1}$ Department of Anatomy, Faculty of Medicine, Kagawa Medical University, 1750-1 Ikenobe, Miki-cho, \\ Kagawa, 761-0793, Japan, ${ }^{2}$ Department of Anatomical Sciences and ${ }^{3}$ Biochemistry, The University of \\ Queensland, St Lucia, Brisbane, Qld, 4072, Australia \\ E-mail: k.bedi@mailbox.uq.edu.au
}

(Accepted May 31, 2000)

\begin{abstract}
Maternal ethanol ingestion during pregnancy can cause fetal alcohol syndrome (FAS) in their offspring. Among the symptoms of FAS, damage to the central nervous system has emerged as one of the most serious problems. We have previously shown that a relatively high dose of ethanol exposure during early postnatal life can cause alterations in spatial learning ability. This ability is controlled, at least in part, by the hippocampal formation. The purpose of the present study was to determine whether exposure of rat pups to ethanol during early postnatal life had effects on the total number of the dentate gyrus neurons. Wistar rats were exposed to a relatively high daily dose of ethanol between postnatal days 10 to 15 . Ethanol exposure was achieved by placing rat pups in a chamber containing ethanol vapour for 3 hours a day. The blood ethanol concentration was found to be about $430 \mathrm{mg} / \mathrm{dL}$ at the end of the exposure period. Groups of ethanol treated (ET), separation controls (SC) and mother reared controls (MRC) were anaesthetised and killed at 16-days-of-age by perfusion with phosphate-buffered $2.5 \%$ glutaraldehyde. The Cavalieri principle was used to determine the volume of subdivisions of the dentate gyrus, and the physical disector method was used to estimate the numerical densities of neurons within each subdivision. The total number of neurons was calculated by multiplying estimates of the numerical density with the volume. There was, on average, about 421,000 granule cells in all three treatment groups. In the hilus region, ET rats had about 27,000 neuronal cells. This value was significantly smaller than the average of 38,000 such neurons estimated to be present in both MRC and SC animals. It is concluded that neurons in the hilus region of the dentate gyrus may be particularly vulnerable to the effects of a high dose of ethanol exposure during PND 10-15. It is likely that this deficit was due to neuronal death induced by some mechanisms related to the ethanol exposure.
\end{abstract}

Keywords: fetal alcohol syndrome, hilar neuron, stereology.

\section{INTRODUCTION}

It is known that maternal ethanol ingestion during pregnancy can cause fetal alcohol syndrome (FAS) in their offspring (Clarren and Smith, 1978). FAS is characterized by specific facial features, microcephaly, growth retardation, and mental retardation (Streissguth and Martin, 1983). Damage to the central nervous system (CNS) has emerged as one of the most serious consequences of FAS. We have previously reported that rats exposed to ethanol during early postnatal life show alterations in their spatial learning ability (Pauli et al., 1995; Tomlinson et al., 1998). It is known that the hippocampal formation is involved in the control of several learning behaviours, including spatial learning. The question arises whether such behavioural deficits are accompanied by morphological alterations in the hippocampus. Development of the human CNS is most rapid during the third trimester of pregnancy ("the brain growth spurt") (Dobbing et al., 1973; 1979). An equivalent period occurs in the first two weeks after birth in rats. It is possible that ethanol exposure during this period may cause morphological changes in the rat hippocampus. In the present study we have used stereological techniques to investigate the effects of early postnatal ethanol exposure on hippocampal neurons in the dentate. 


\section{MATERIALS AND METHODS}

\section{ANIMALS AND ETHANOL ADMINISTRATION}

Pregnant Wistar rats supplied from the University of Queensland Central Animal Breeding House were used. They were housed in individual cages and checked at 9.00 am each day in order to determine whether they had given birth. The day of birth was defined as PND 0. On PND 2 pups from three separate litters were removed from their mothers and placed together in a temporary holding cage. The pups from this pool were then randomly assigned back to the lactating mothers such that each mother received 12 pups. These litters were then randomly assigned to either ethanol treatment (ET), separation control (SC) or mother-reared control (MRC) groups. The exposure to ethanol was achieved by a vapour inhalation method similar to that described by Karanian et al. (1986). Specifically, on each day between PND 10-15 all of the pups from a given litter assigned to the ET group were removed from their "mother" between the hours of $10 \mathrm{am}$ to $1.00 \mathrm{pm}$ and placed in a holding cage containing wood shavings. This was located in an enclosed perspex chamber (600x600x1,100 mm). Ethanol vapour mixed with medical grade air was allowed to flow into this chamber at a rate of $10 \mathrm{~L} /$ minute. The concentration (mean $\pm \mathrm{SD} ; \mathrm{n}=9$ ) of ethanol in the chamber was controlled to be about $76.3 \pm 15.9 \mathrm{mg} / \mathrm{L}$. Pilot experiments had shown that these concentrations of ethanol vapour produced similar blood alcohol concentrations in the different aged rats used. After the three hour treatment period each day the pups were weighed and returned to their "mother". The pups within the SC litters were also removed from their mother for a period of three hours per day between PND 10-15. During this period of separation these pups were placed in a chamber under similar conditions as the ET groups except that ethanol vapour was not added to the air. The pups within the MRC groups were allowed to remain with their mother for the duration of the experiment. Blood alcohol concentrations (BAC) in some of the ethanol treated rats were measured immediately after the period of ethanol exposure on PND 10, 12 and 15. The enzymatic method described by Lundquist (1959) was used for these determinations. The pups used for this purpose were not those used in the main part of the experiment.

\section{TISSUE PREPARATION.}

At 16 days of age groups of ET, SC and MRC pups were deeply anaesthetised with a mixture $(0.1 \mathrm{~mL} / \mathrm{kg}$ of body weight $)$ of 50:50 (v/v) Ketamine $(100 \mathrm{mg} / \mathrm{mL}$; Apex Laboratories, Australia) and Xylazine $(20 \mathrm{mg} / \mathrm{mL}$; Cooper Animal Health, Australia) and perfused intracardially with physiological saline followed by a fixative containing $2.5 \%$ glutaraldehyde in $0.1 \mathrm{M}$ phosphate buffer (pH 7.4). Each group contained nine pups with no more than three from any given litter. After perfusion the brains were removed from the skull and weighed. The right hippocampus was dissected out from each brain and post-fixed in 1.0\% osmium tetroxide, stained with $5.0 \%$ uranyl acetate and embedded in epoxy resin. Serial $2 \mu \mathrm{m}$-sections were cut horizontally and every 200th section was picked up for stereological analysis. The first of these sections through a given block to show any sign of containing hippocampal tissue was numbered as the first section, with all subsequent sections being numbered sequentially. For this purpose a number between 1 to 200 was selected at random. For example, if 17 was selected the $17 \mathrm{th} / 18$ th sections, $217 \mathrm{th} / 218$ th sections etc., were picked up and stained with $0.1 \%$ toluidine blue. The actual mean section thickness (t) was determined using the step method (Evans and Howard, 1989) and found to be $2.04 \mu \mathrm{m}$. This procedure was repeated until the given hippocampus was exhaustively sectioned. This sampling strategy is generally referred to as a systematic, uniformly random sampling procedure.

\section{STEREOLOGICAL PROCEDURE}

Identification of hilus region and the dentate granule cell layer of the hippocampus was based on morphological features and locations of the cells (Sousa et al., 1997; West et al., 1991). Hilar neurons and granule cells were counted separately. Neurons were distinguished from glial cells according to the criteria described by Ling et al. (1973). The volumes of the hilus region and granule cell layer were determined using the Cavalieri principle (Gundersen and Jensen, 1987). For this, one section from each consecutive pair sampled from each hippocampus was, in turn, projected onto a screen at a magnification of x87.5 using a Zeiss Microprojector. Each image was superimposed at random with a test lattice having a regular array of test points $10 \mathrm{~mm}$ apart. Each point represented an area (u) of $0.013 \mathrm{~mm}^{2}$ in the section plane. The total number $(\mathrm{P})$ of test points falling on hilus region or granule cell layer was counted. These counts for any given 
subdivision are related to the volume (V) of the subdivision by the relationship:

$$
\mathrm{V}=\mathrm{u} \cdot \sum \mathrm{P} \cdot \mathrm{t} \cdot \mathrm{N} / \mathrm{n}
$$

where $\mathrm{N}=$ total number of serial sections through the hippocampus, $\mathrm{n}=$ the number of these sections sampled for the point counting procedure, and $\mathrm{t}=$ the mean thickness of the serial sections (determined as described above).

\section{ESTIMATION OF THE NUMERICAL DENSITY}

The numerical densities of neurons in the dentate gyrus were estimated using the disector method (Sterio, 1984). This method involves examining two serial sections of known distance (h) apart. The number $\left(\mathrm{Q}^{-}\right)$of profiles which appear in one section (sampling section) but not in an adjacent serial section (look-up section) in a given area of tissue is determined. In this study, as consecutive serial sections were used as the sampling and look-up sections, the distance between sections (h) was equal to the section thickness (t). Each section in a given pair and for a given hippocampal regions was, in turn, examined under a microscope fitted with video camera. This was connected to a computer fitted with a frame capture card so that any image required could be immediately stored in digital format in the computer memory and later printed using a laser printer. Each hippocampal region to be examined was scanned under the microscope in a raster fashion. A systematic, uniformly random sampling procedure was used to select fields of view for further analysis. The image of the field selected was "captured" and stored in computer memory. The corresponding field was then located in the consecutive serial section and its image again stored on computer. The hilus region was examined using a $\mathrm{x} 20$ objective whilst granule cell layer was examined using a $x 40$ objective. The final magnification of the printed images was found to be $\mathrm{x} 940$ and $\mathrm{x} 1,810$ respectively. In pilot experiments it was found that in order to obtain acceptable precision of the estimates of neuronal density (and hence cell number) under our experimental conditions, it was necessary to sample about 40 pairs of micrographs from hilus regions and about 15 pairs from granule cell layer per animal. Counts were made of the total number of neuronal nuclear profiles appearing in the micrographs from the "sampling" section but not appearing in the corresponding micrographs of the "look-up" sections. In order to increase efficiency, each micrograph was used in turn, first as the "sampling" section and then as the "look-up" section. All counting procedures were carried using the "2-D counting rule" (Gundersen, 1977). The average number of profiles counted (Q') per region per animal was 127. Estimates of the numerical density of neurons $\left(\mathrm{N}_{\mathrm{V}}\right)$ in any given region was obtained using the formula (Sterio, 1984),

$$
\mathrm{N}_{\mathrm{V}}=\sum \mathrm{Q}^{-} / \mathrm{a} \cdot \mathrm{h}
$$

where $\mathrm{a}=$ total area of test section examined for that given region.

\section{ESTIMATION OF TOTAL NUMBER OF NEURONS}

The total number of pyramidal neurons in the hilus region and granule cell layer was estimated by multiplying the volume of the region by the corresponding numerical density of neurons.

\section{STATISTICS}

The data was analysed by appropriate analysis of variance (ANOVA) procedures. Post hoc tests were carried out where appropriate using Tukey-Kramer's test (Sokal and Rohlf, 1981). All statistics were carried out using Minitab (Version 12) on an IBMcompatible computer.

\section{RESULTS}

\section{BLOOD ETHANOL CONCENTRATION}

The mean blood ethanol concentration of rats exposed to ethanol vapuor was $432 \pm 38 \mathrm{mg} / \mathrm{dL}$ (mean \pm SEM; $\mathrm{n}=21$ ).

\section{BODY WEIGHTS}

The mean \pm SEM body weights of MRC, SC and ET rats on days 10 and 15 are shown in Table 1. Two-way ANOVA of this data revealed a significant main effect due to the Age factor (df 1, 178: $\mathrm{F}=662.05, \mathrm{p}<0.0001$ ) but not the Group factor (df 2, 178: $F=1.28)$. However, the Group $\times$ Age interaction ( $\mathrm{df} 2,178: \mathrm{F}=13.92, \mathrm{p}<0.0001$ ) was statistically significant. Post-hoc analysis using Tukey-Kramer's test showed that this was due to the relative alteration in the body weight of the ethanol treated animals. Thus, whilst at the beginning of the treatment period there was no significant difference in body weight between the pups allocated to the three groups, by the end of the treatment period the ET rats had small but significant deficits in body weight compared with both MRC and SC animals. 


\section{BRAIN WEIGHTS}

Table 2 shows the mean \pm SEM for brain weights of the MRC, SC and ET rats at 16 days of age. Oneway ANOVA of this data revealed significant between-group differences (df 2, 24: $F=10.79$, $\mathrm{p}<0.0001)$ among three groups. Post-hoc analysis with Tukey-Kramer's test revealed that the brain weights of ET rat was significantly smaller compared to both MRC and SC rats.

\section{NUMERICAL DENSITY OF NEURONS}

The mean \pm SEM numerical densities of neurons are presented in Table 3 . There were between about 23,000 and 26,000 neurons per $\mathrm{mm}^{3}$ in the hilus region and about 283,000 and 303,000 granule cells per $\mathrm{mm}^{3}$ in the granule cell layer in all groups respectively. One-way ANOVA showed that there were no significant main effects of Groups in these measures for hilus region ( $\mathrm{df} 2,24: \mathrm{F}=1.29)$ and granule cell layer ( df 2, 24: $\mathrm{F}=0.54)$.

\section{VOLUME OF SUBDIVISION OF THE HIPPOCAMPUS}

The mean \pm SEM volumes of the hilus region and granule cell layer in the 16-day-old rats are presented in Table 3. One-way ANOVA revealed that the volume of the hilus region showed a significant Group effect (df 2, 24: $\mathrm{F}=5.00, \mathrm{p}<0.05$ ). TukeyKramer's post hoc analysis showed that the volume of the hilus region in ET rats was significantly smaller than that in both MRC and SC animals. There were no significant Group effect (df 2, 24: $\mathrm{F}=0.09$ ) on the volume of granule cell layer.

\section{TOTAL NUMBER OF NEURONS}

The mean \pm SEM total number of neurons are shown in Table 3. There was between 398,000 and 441,000 granule cells irrespective of the group of rats studied. There were no significant effects of Groups (df 2, 24: $F=0.85$ ) on any of these three measures of cell numbers. However, examination of the hilus region of the dentate gyrus showed that whilst MRC and SC rats had about 38,000 neurons there was only about 27,000 such cells in ET animals. This was reflected in a significant Group effect (df 2, 24: $\mathrm{F}=8.62, \mathrm{p}<0.02)$ in the one-way ANOVA test for this data. Post-hoc tests showed that the total number of such neurons in the hilus region of ET rats was significantly lower than that found in both the MRC and SC animals.

Table 1. Mean \pm SEM body weights of MRC, SC and ETRats at PND 10 and 15.

\begin{tabular}{lll}
\hline Group & PND 10 & PND 15 \\
\hline MRC & $21.7 \pm 0.4(32)$ & $33.00 \pm 0.5(29)$ \\
SC & $21.5 \pm 0.3(32)$ & $32.57 \pm 0.5(29)$ \\
ET & $23.2 \pm 0.6(32)$ & $30.08 \pm 0.5(27)$ \\
\hline
\end{tabular}

The number in parenthesis shows a number of animals examined.

Table 2. Mean \pm SEM brain weights of 16-day-old ET rats and their controls.

\begin{tabular}{ll}
\hline Group & Brain weight \\
\hline MRC & $1.41 \pm 0.02(9)$ \\
SC & $1.39 \pm 0.02(9)$ \\
ET & $1.27 \pm 0.03(9)$ \\
\hline
\end{tabular}

The number in parenthesis shows a number of animals examined.

Table 3. Data on numerical density, volume and total number of neurons in dentate gyrus of 16-day-old MRC, SC and ET rats.

\begin{tabular}{|c|c|c|c|c|c|}
\hline Group & & Hilus & & Granule cell layer & \\
\hline \multirow[t]{3}{*}{ MRC } & $\mathrm{N}_{\mathrm{V}}\left(/ \mathrm{mm}^{3}\right)$ & $26,100 \pm 900$ & (9) & $302,500 \pm 15,700$ & (9) \\
\hline & $\mathrm{V}\left(\mathrm{mm}^{3}\right)$ & $1.46 \pm 0.07$ & (9) & $1.46 \pm 0.07$ & (9) \\
\hline & $\mathrm{T}$ & $38,100 \pm 2,000$ & (9) & $441,400 \pm 31,100$ & (9) \\
\hline \multirow[t]{3}{*}{ SC } & $\mathrm{N}_{\mathrm{V}}\left(/ \mathrm{mm}^{3}\right)$ & $25,900 \pm 1,600$ & (9) & $292,800 \pm 10,100$ & (9) \\
\hline & $\mathrm{V}\left(\mathrm{mm}^{3}\right)$ & $1.48 \pm 0.06$ & (9) & $1.46 \pm 0.09$ & (9) \\
\hline & $\mathrm{T}$ & $38,000 \pm 2,100$ & (9) & $424,700 \pm 21,600$ & (9) \\
\hline \multirow[t]{3}{*}{ ET } & $\mathrm{N}_{\mathrm{V}}\left(/ \mathrm{mm}^{3}\right)$ & $22,600 \pm 2,400$ & (9) & $283,000 \pm 13,400$ & (9) \\
\hline & $\mathrm{V}\left(\mathrm{mm}^{3}\right)$ & $1.21 \pm 0.07$ & (9) & $1.42 \pm 0.06$ & (9) \\
\hline & $\mathrm{T}$ & $26,600 \pm 2,500$ & (9) & $398,400 \pm 15,300$ & (9) \\
\hline
\end{tabular}

Each value is represented as mean $\pm \mathrm{SEM} ; \mathrm{N}_{\mathrm{V}}$, numerical density of neurons; $\mathrm{V}$, volume of the sub-division; $\mathrm{T}$, total number of neurons. The number in parenthesis shows a number of animals examined. 


\section{DISCUSSION}

The results of this study show that a high dose of ethanol exposure to rat pups during PND 10-15 can cause a significant deficit in total number of neuron in the hilus region of the dentate gyrus at 16-day-of age. This deficit was due to the deficit in the volume of the hilus region in ET rats. However, the total number of granule cells in granule cell layer showed no significant changes. These hilar neurons are important inter-neurons that play a crucial role in maintaining the neuronal activity in the hippocampus (Amaral and Witter, 1995). The exact functional consequences of their loss seen in this study are unknown at present. We (Pauli et al., 1995; Tomlinson et al., 1998) have previously reported that exposure of rats to ethanol can have deleterious effects on spatial learning behaviour as measured in the Morris water maze. The exact mechanism of the regional difference in vulnerability of dentate gyrus neurons is unknown at present. In the present study ethanol administration to rat pups was during PND 10-15. Hilar neurons are generated during late gestation whilst dentate gyrus granule cells are generated mainly during the postnatal period (Bayer, $1980 \mathrm{a}, \mathrm{b}$ ) and continue to be produced at a low rate well into adulthood (Bayer et al., 1982). It is therefore, concluded that the deficit in neuronal number in the hilus region is likely to be due to neuronal cell death and that this was somehow induced by ethanol exposure. It may be, at least, partially related to the timing of the ethanol exposure with respect to the period of neurogenesis for given neurons although this is unlikely to be the complete story.

It has been reported that the hilus region of the dentate gyrus is particularly vulnerable to environmental insults, such as alcohol exposure (West et al., 1986), epileptic state (Sloviter, 1987), head trauma (Lowenstein et al., 1992), ischemia (Johansen et al., 1987) and malnutrition (Andrade, 1995). The damage induced ethanol exposure (West et al., 1986) to rat hippocampus is characterised by a selective neuronal loss (16\%) in the hilus region of the dentate gyrus. This is seen in 10-day-of-age rats exposed to ethanol during PND 4-10 at a blood ethanol concentration of $380 \mathrm{mg} / \mathrm{dL}$. They (West et al., 1986) counted the numbers of pyramidal and granule cell nuclear fragments in a single section from the "midtemporal" level of each hippocampus. Whilst overall their result is consistent with our present findings, the counting procedure used by West et al. (1986) was severely limited in its scope and likely to yield potentially serious errors (Gundersen, 1986). Modern stereological techniques are capable of allowing the unbiased estimate of total numbers of cells in an organ. Such values are easier to conceptualise and compare than arbitrary counts such as number of "nuclear fragments" in a single section taken through one level of the hippocampus.

In conclusion, the presnt study has shown that exposure to ethanol during early life can cause a deficit in total the number of hilar neurons in the dentate gyrus. The mechanisms underlying ethanolinduced hilar injury remain unknown at present. Our hypothesis is that the lower volume of the hilar region may have partially been due to the loss of some of the neurons, but may also have been influenced by the extent of dendritic arborisation in this region. Golgi studies have shown that ethanol exposure results in morphological alterations in the length and degree of branching of dendrites and in the number and proportions of various types of dendritic spines (Davies and Smith, 1981). Such effects may well result in significant deficits in the volume of the neuropil and hence overall volume of a given region of the brain.

A preliminary report of some of the data was presented at the $X^{\text {th }}$ International Congress for Stereology, Melbourne, Australia, 1-4 November 1999.

\section{REFERENCES}

Amaral D, Witter M (1995). Hippocampal Formation. In: Paxinos G, editor. The Rat Nervous System. San Diego: Academic Press, 443-93.

Andrade J, Madeira M, Paula-Barbosa M (1995). Effects of long-term malnutrition and rehabilitation on the hippocampal formation of the adult rat. A morphometric study. J Anat 187:379-93.

Bayer SA (1980a). Development of the hippocampal region in the rat. I. Neurogenesis examined with $3 \mathrm{H}-$ thymidine autoradiography. J Comp Neurol 190:87114.

Bayer SA (1980b). Development of the hippocampal region in the rat. II. Morphogenesis during embryonic and early postnatal life. J Comp Neurol 190:115-34.

Bayer SA, Yackel JW, Puri PS (1982). Neurons in the rat dentate gyrus granular layer substantially increase during juvenile and adult life. Science 216:890-2.

Clarren SK, Smith DW (1978). The fetal alcohol syndrome. N Engl J Med 298:1063-7.

Davies DL, Smith DE (1981). A Golgi study of mouse hippocampal CA1 pyramidal Neurons following perinatal ethanol exposure. Neurosci Lett 26:49-54. 
Dobbing J, Sands J (1973). Quantitative growth and development of human brain. Arch Dis Child 48:757-67.

Dobbing J, Sands J (1979). Comparative aspects of the brain growth spurt. Early Hum Dev 3:79-83.

Evans SM, Howard V (1989). A simplification of the "step" method for estimating mean section thickness. J Microsc 154:289-93.

Gundersen HJ, Jensen EB (1987). The efficiency of systematic sampling in stereology and its prediction. $\mathbf{J}$ Microsc 147:229-63.

Gundersen HJG (1977). Notes on the estimation of the numerical density of arbitrary particles: The edge effect. J Micros 111:219-23.

Gundersen HJG (1986). Stereology of arbitrary particles. A review of unbiased number and size estimators and the presentation of some new ones, in memory of William R. Thompson. J Microsc 143:3-45.

Johansen FF, Zimmer J, Diemer NH (1987). Early loss of somatostatin neurons in dentate hilus after cerebral ischemia in the rat precedes CA-1 pyramidal cell loss. Acta Neuropathol (Berl) 73:110-4.

Karanian J, Yergey J, Lister R, D’Souza N, Linnoila M, Salem NJ (1986). Characterization of an automated apparatus for precise control of inhalation chamber ethanol vapor and blood ethanol concentrations. Alcohol Clin Exp Res 10:443-7.

Ling E, Paterson J, Privat A, Mori S, Leblond C (1973). Investigation of glial cells in semithin sections. I. Identification of glial cells in the brain of young rats. $\mathrm{J}$ Comp Neurol 149:43-71.

Lowenstein DH, Thomas MJ, Smith DH, McIntosh TK (1992). Selective vulnerability of dentate hilar neurons following traumatic brain injury: a potential mechanistic link between head trauma and disorders of the hippocampus. J Neurosci 12:4846-53.
Lundquist F (1959). The determination of ethyl alcohol in blood and tissues. Methods in biochemical analysis, 217-49.

Pauli J, Wilce P, Bedi KS (1995). Spatial learning ability of rats following acute exposure to alcohol during early postnatal life. Physiolo Behav 58:1013-20.

Sloviter RS (1987). Decreased hippocampal inhibition and a selective loss of interneurons in experimental epilepsy. Science 235:73-6.

Sokal RR, Rohlf FJ (1981). Biometry, $2^{\text {nd }}$ edition. New York: W.H. Freeman and company.

Sousa N, Madeira MD, Paula-Barbosa MM (1997). Structural alterations of the hippocampal formation of adrenalectomized rats: an unbiased stereological study. J Neurocytol 26:423-38.

Sterio DC (1984). The unbiased estimation of number and sizes of arbitrary particles using the disector. J Microsc 134:127-36.

Streissguth AP, Martin JC (1983). Prenatal effects of alcohol abuse in humans and laboratory animals. In: Kissin B, Begleiter $\mathrm{H}$, eds. The pathogenesis of alcoholism. New York: Plenum Publishing, 539-89.

Tomlinson D, Wilce P, Bedi KS (1998). Spatial learning ability of rats undernourished during early postnatal life. Physiol Behav 51:1001-7.

West JR, Hamre KM, Cassell MD (1986). Effects of ethanol exposure during the third trimester equivalent on neuron number in rat hippocampus and dentate gyrus. Alcohol Clin Exp Res 10:190-7.

West MJ, Slomianka L, Gundersen HJ (1991). Unbiased stereological estimation of the total number of neurons in the subdivisions of the rat hippocampus using the optical fractionator. Anat Rec 231:482-97. 